\section{THE PLANET VENUS}

$\mathrm{M}$ E. L. TROUVELOT has published a most important and extensive paper on some observations of the planets Venus and Mercury, which for many years past have been occupying his attention. The physical features of the other planets have been treated on previous occasions in like manner, and have extended our knowledge very considerably, so that the reader of this work will be sure to find something really new in the great number of observations that are here recorded. Up to the month of April, I882, the observations were made at Cambridge, United States; but since then Meudon has been the seat of operations; the air at the latter place did not prove so pure as that in the States, and the horizon not being so open, the number of observations of course was somewhat reduced.

In the work which we have before us the author divides this subject up into nine sections, and we cannot do better than treat of each of them in turn, commencing with the visibility of Venus to the naked eye in full daylight. The best way is, he says, to use the tele cope as a pointer, directing it to her by means of the circles; by then looking along the telescope tube he has been able to see her at every point of her orbit, when her angular distance from the sun towards inferior conjunction was not less than $10^{\circ}$, and also towards superior conjunction when she was not less than $5^{\circ}$. Her visibility depended to some extent on the phase she represented, for it is known that the eye can distinguish more easily a disc small and distant than a comparatively larger and nearer crescent. At Cambridge it seems to have been more or less the rule, while at Meudon it was the exception, to see Venus in the daytime, the atmospheric conditions at the latter place being comparatively very bad.

With regard to the general aspect of Venus nothing very striking has been noticed; the part of the limb turned towards the sun, as recorded by other observers, always appeared more brilliant than the more central portions extending towards the terminator. Sometimes the limb was not so bright as usual, being observed to be "dull and without brilliancy," one very noticeable time occurring on April i 5,1878 .

Under favourable conditions, whitish and greyish spots can be seen on the surface of Venus, which, at any time, are very difficult to observe. These different-tinted spots give, according to $M$. Trouvelot, indications of being at different levels. The whitish spots, situated near the terminator, produce on it slight deformations, and seem to so alter it as to suggest that these spots are at a higher level than the other parts. The greyish spots, on the other hand, when situated in about the same positions, also deform the terminator to a small extent, but in an opposite way to those just mentioned, suggesting that these spots lie at a lower level than the parts near them. These two kinds of spots have another peculiarity which has been particularly noticed, and that is their size ; the white ones seem to assume a round or slightly oval form, and are nearly always small, but the grey spots are generally of an elongated shape, and are of very large proportions, forming sometimes straight bands. The interval between the appearance and disappearance of these spots is not long; in their formation they are analogous, as M. Trouvelot says, "avec ces taches diffuses des couches nuageuses continues de notre atmosphère précèdent les pluies, et qu'un simple jeu de lumière fait naître ou disparaître." Their contours are always very vague, the whites being a little less brilliant, and the greys a little less dark.

One of the largest spots that has been diligently observed was that which appeared on the 3 rd September, 1876. Its size, as will be seen from the figure, was, comparatively speaking, enormous, occupying nearly a third of the illuminated visible surface. At its north and south extremities it was separated from the terminator by a large white band, the north one being considerably larger than the southern one. Up to the roth of the same month this spot was still visible, but after that date no trace of it at all could be found. Curiously enough, on February I3th, I89I, another large grey spot (Fig. 2), bordered with white, made its appearance, and was very similar to the one we have just mentioned, both with regard to its position and form-indeed, the resemblance was so striking that the spots were considered the same.

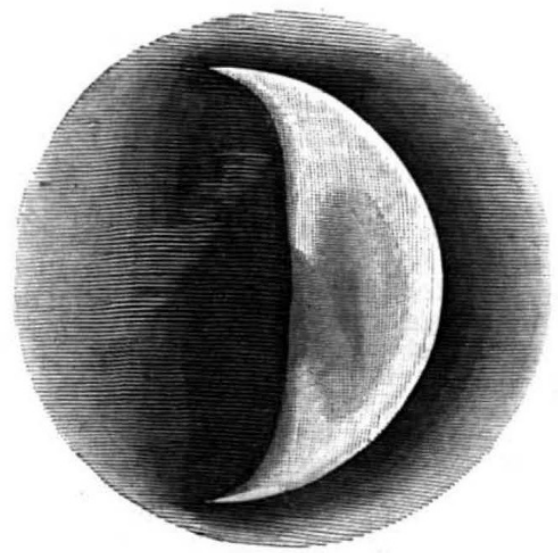

F1G. 1. - Showing the large spot on Septeınber 3,1876 .

Why it should have disappeared so soon in 1876 , and become visible again in $189 \mathrm{I}$, is a mystery which is hard to fathom.

Perhaps one of the most interesting features visible on the surface of Venus are the two snow caps (Figs. 3 and 4) at the extremities of her poles. These spots, as M. Trouvelot says, surpass in brilliancy and importance all that he has ever observed. In 1877 , on November I $3^{\text {th }}$ a white spot was seen at the north limit of Venus ; its brilliancy attracted considerable attention, resembling

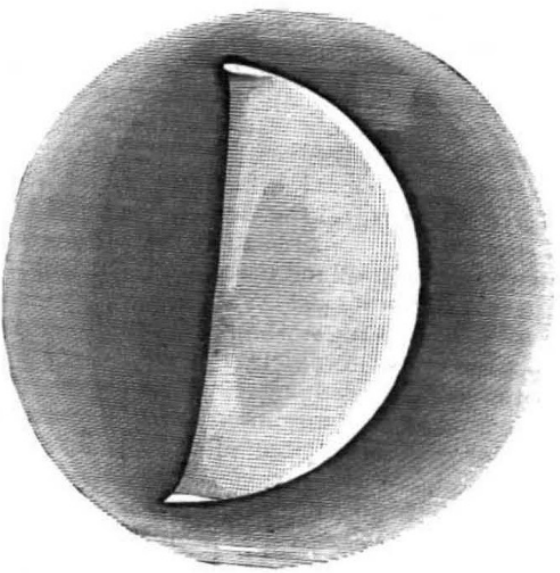

Fic. 2.-Large spot visible on February $18,18 \mathrm{gr}$.

very much those situated on Mars. On the following day, another spot, also very striking and of the same character, diametrically opposed, was observed. The question then arose as to the cause of these spots, and we may here quote an entry that was written in the observer's book on the 17 th of the same month :- "Est-ce que Vénus aurait des taches blanches semblables aux taches polaires de Mars?" The seeing of these spots was by no means a difficult task, and it seemed certain that if

NO. I I 94. VOL. 46] 
they were snow caps as suggested, perhaps they had been previously observed. This was the case. On June 9 and 17, July 20, August I and 27, I876, and February 5, 1877, observations of these spots had been recorded in the notebook, but owing to their not having attracted very great attention at the time, they were regarded as ordinary spots. That they are analogous to the white spots on Mars is now undoubted : they have the form of a uniform white segment of a circle, which, when seen edgeways, appear as simple lines; they are always exactly $180^{\circ}$

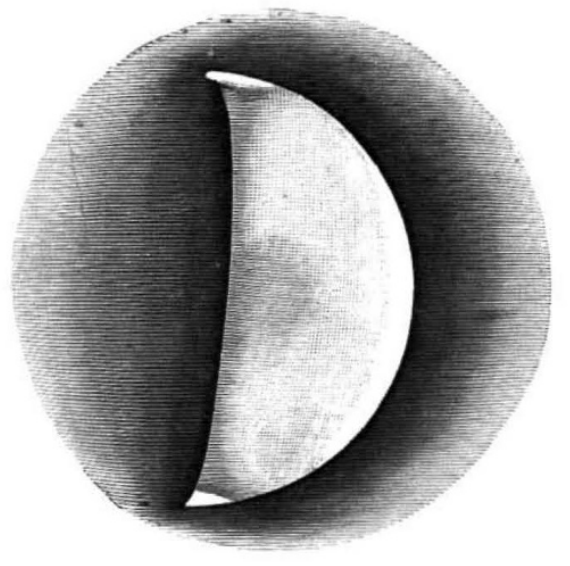

F1:3.-The snow caps, February $20,: 89 \mathrm{r}$, rob. $45^{\mathrm{m}}$

apart ; sometimes only one is seen because the other is not lighted up by the sun; they are always approximately near the terminator, and seem to oscillate backwards and forwards, balanced, so to speak, around the axis of the planet; and, lastly, they are of a permanent nature, their disappearances being due not to their annihilation, but simply to the fact that they cannot be seen when receiving no light upon them. One main feature in which they differ from the spots on Mars is that they neither increase

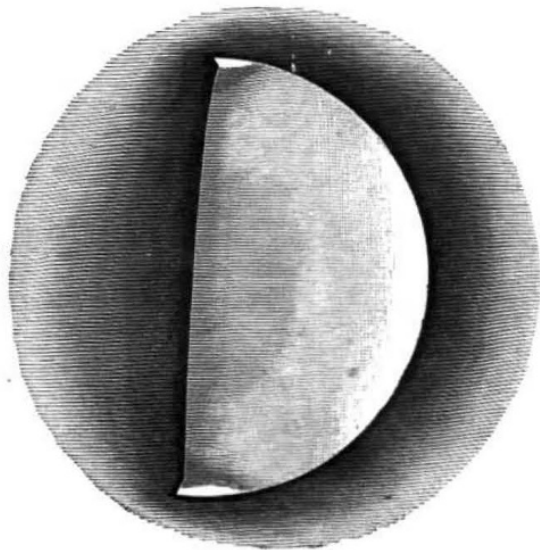

Fig. 4.-The snow caps, February 25, 1891, 10h. $15 \mathrm{~m}$

nor decrease with the seasons, at any rate to a sufficient extent to be sensibly noticed.

When Venus is in a favourable position for observation many details on these spots have been recorded. M. Trouvelot mentions here some bright spots (Figs. 5 and 6), which seem to be very numerous, and resemble the bright specks which are seen on the terminator of the moon, "sinon qu'elles sont plus brillantes, surtout sur leur bord interne, et qu'au lieu de petits cratères, elles sont entièrement couvertes et hérissées de pics et d'aiguilles, qui, parfois, réfléchissent la lumière avec une si grande intensité, que ce bord apparaît tout constellé d'étoiles alignées comme les grains d'un collier de pierres précieuses, sans quelques irrégularités dans cet alignement." The whole appearance seems to suggest that the spots are at a higher level than the contiguous parts of the planet situated at the edge. This idea is also further borne out when the phase of the planet is a small crescent, for then much more of the polar cap is found to be visible than should be the case if the form of the phase

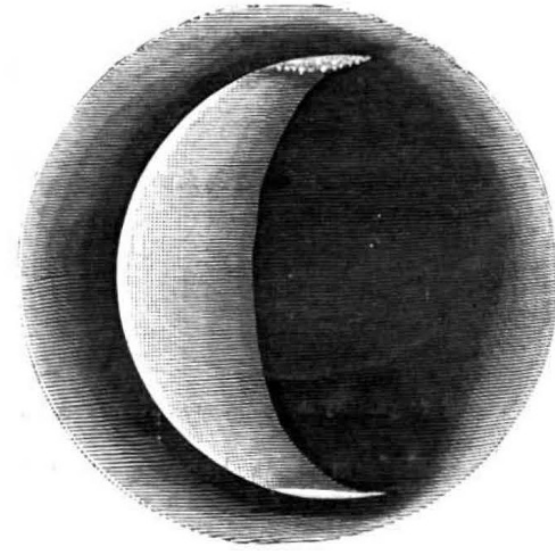

Fig. 5,-Details on the snow caps, January 19,1878 .

was an exact crescent. In many cases a penumbra has distinctly been seen, and in one of them it was so strong and distinct on that part of the terminator lying between the two polar caps, that it lasted for a month, the spots remaining clear and brilliant throughout their entire length. Ever since the year 1700 , observers of Venus have remarked these two spots that occupy the polar regions. La Hire and Derham, observing the inequalities of the surface at the extremities of the crescent, believed

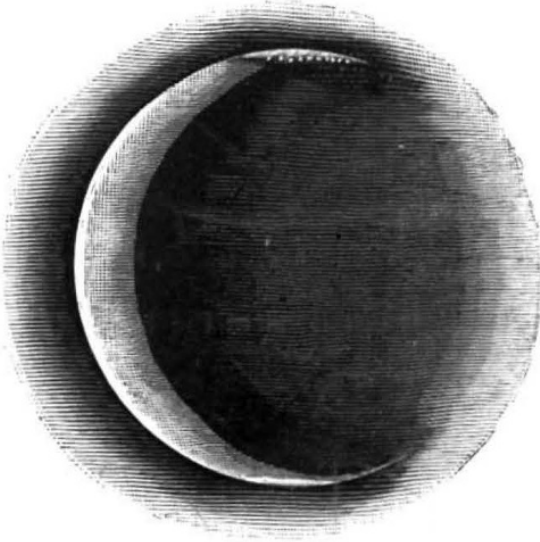

FIG. 6.-The snow caps, February 5, 1878.

that they could be produced by mountains higher than those on the moon. Bianchini at Rome, Schroeter, Gruithuisen, and several others, all have reported the existence of such markings, but they were never led to conclude that they were snow caps analogous to those on Mars.

To obtain a general idea of the ruggedness and smoothness of the planet's surface, the terminator has helped to considerably distinguish the high and low elevations and depressions respectively. The surface of Venus from

No. I I 94. vor. 46$]$ 
such observations as these has been found to be considerably studded not only with small, but with great differences of configuration, the terminator varying greatly in many phases of the planet. M. Trouvelot's results

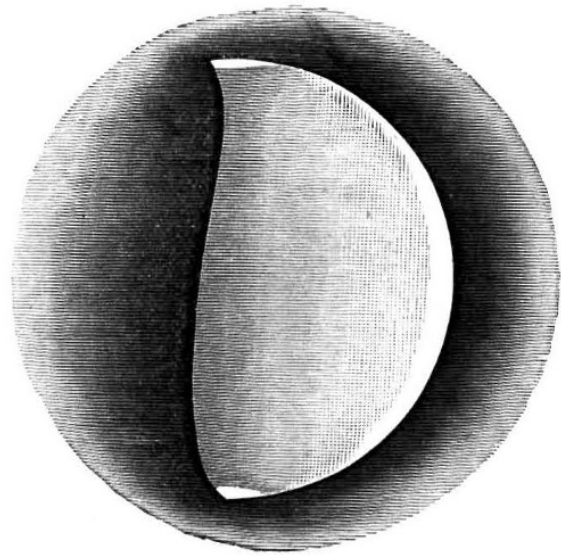

FIG. 7.-Showing irregularity of Terminator, November 23,1877 .

show that these deformations become most apparent when Venus is at her greatest eastern and western elongations. Sometimes one half of the terminator is seen concave, while at the same time the other is convex

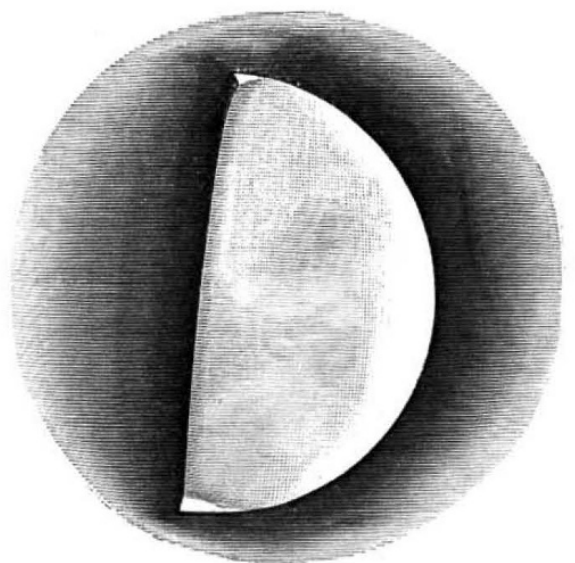

FIG 2,-Showing indentations at the horns, February $28,1891$.

(Fig. 7); small indentations at the horns (Fig. 8) also seem to be of common occurrence, and occasionally the curve of the terminator is perfect, no trace of any irregularity being noticed. Not only then does the terminator

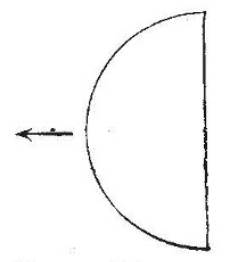

Frg. 9.-February 5,

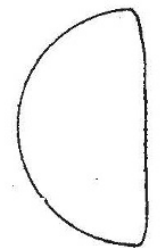

FIG. xo.-February 5, 5h. 43 m.

change in form, but changes are found to occur very rapidly in intervals of only a few hours. To take one case out of many, we may quote the instance recorded in $188 \mathrm{I}$ on February 5 at 2 p.m. (Figs. 9 and Io). At NO. I I 94, VOL. 46]

this time the terminator appeared as a straight line showing Venus then in apparent quadrature, but at $5 \mathrm{~h} .43 \mathrm{~m}$. this line was quite gibbous, and its curve regular. A very important point about the repetitions of the same deformations is that they do not occur at exactly the same time each day, but appear to change the hour of observation, "the periodicity of these phenomena, if periodicity there is, not being exactly twenty-four hours."

From a long series of observations, the most striking irregularities were found at the extremities of the ter-

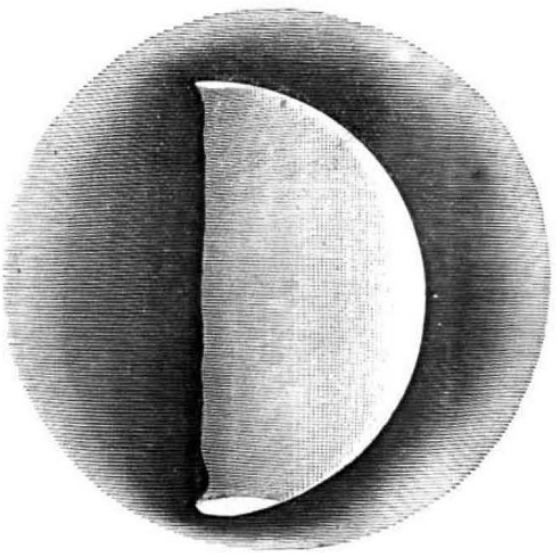

FIG. II.-Showing tlie shape of the horns, September 27,1876 .

minator close to the edge of the pole caps, where deep niches were often recorded. These indentations were noticed to be generally of different sizes and shapes, sometimes the north one being larger than the southern one, and vice versâ. They also underwent very rapid changes even in the space of a few hours, a case occurring on September 27,1876 (Fig. I I). "At one time the extremity of one of the horns would be more or less truncated, when the other would be sharp, and some hours later the

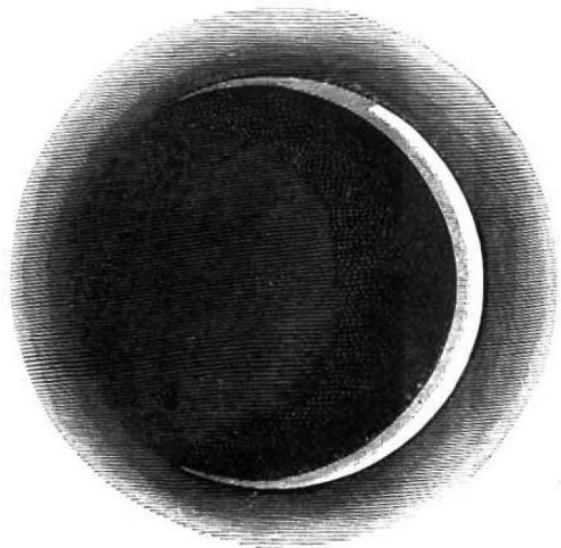

Fig. I2.-An abnormal extent of the crescent, May r3, r88r.

reverse would be the case, that which was sharp being truncated, and that which was truncated being sharp." M. Trouvelot concludes that his observations bring out a very important fact--." qu'il a une relation très étroite entre les déformations les plus importants subies par le terminateur et par les cornes, et les taches polaires de la planete"

When Venus approaches inferior conjunction with the sun, its crescent gradually diminishes until the illuminated surface is turned exactly away from us. Just before this position is reached, the crescent has been found to present 
many curious features. The most prominent of them is that this fine crescent is sometimes observed to extend to a greater angular extent than $180^{\circ}$ (Fig. 12), $260^{\circ}$ of the limb of the planet having once been recorded. Sometimes, by adopting special precautions, the whole circumference has been observed, the obscured disc being completely surrounded by a pale and thin luminous ring. This, as M. Trouvelot says, is of very rare occurrence, for it has happened that although the greatest precautions have been taken, no trace of the planet could be found.

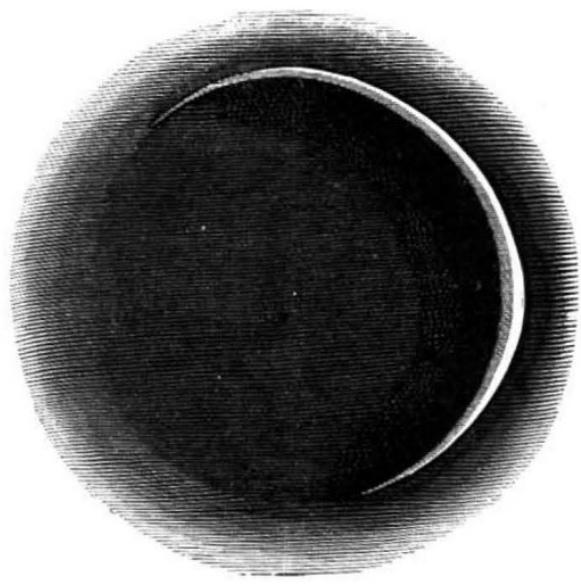

FIG. 13.-Showing the bulging out of the crescent as seen on February 24, $\mathrm{r} 878$.

When the crescent is extremely fine, great irregularities have been noticed to mar the continuity of its curve; they differ also not only at different but at the same con junctions according as the planet is to the east or west of the sun.

Another fact that has been observed relates to the bulging out of the planet (Figs. 13 and I4) at some parts of its visible limb. This was especially noticed in the month of February, I 878 ; while the crescent was being

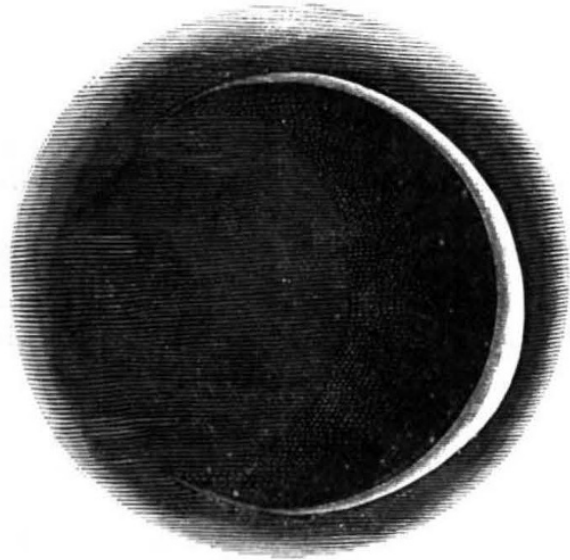

Fic. $x_{4}--$ The crescent as seen on Eebruary 26,1878 .

looked at, the south-south-east portion seemed to suddenly appear thicker than the remaining part. In fact, the observer in the first instance thought it might have been due to some optical defect in the instrument; but subsequent observation showed that this was not the case, a real change of form having taken place. Two days later this deformation was still more noticeable, the thickness of the visible section being about double what it would have been had it been in its normal condition.

No. I 94 , VOL. 46$]$
Perhaps one of the most important points referred to in this work is the determination of the period of rotation by means of the spots. This question of rotation is one that has baffled many observers, for the difficulty that has presented itself lies not only in the proper motions of the spots themselves, but in the identification of the same spots after brief periods of time. Glancing over some of the periods already obtained, we find that Schroeter deduced from his observations a rotation of about 24 h., basing his value on the movement of a small isolated spot situated in one of the horns. Fritsch's value of $23 \mathrm{~h} .22 \mathrm{~m}$., and P. de Vico's 23h. $21 \mathrm{~m}$. 21s., are both also of about the same length. From observations by $D$. Cassini and F. Bianchini, we have a very wide deviation, the periods of rotation being reckoned in days, the former arriving at a value of 23 days, and the latter at a somewhat larger one of 24 days 8 hours. Coming now to Schiaparelli's value of 225 days, we have here altogether a new departure, the planet rotating on its axis in the same time as it revolves round the sun.

With such values as these it will be at once seen that there is something radically wrong with the spots or their positions on the planet's surface; in some cases, of course, there might have been instances of mistaken identity, but with such an observer as Schiaparelli, who very definitely settles upon a 225 daily period obtained from direct observation, it is hard to conceive that any such sources of error would not have been remarked.

The observations which we have now before us bear out Schroeter's view of a short rotation, Prof. Trouvelot telling us that they were made during the years I 876-78 under exceptionally good conditions. One very interesting point which is of great importance is the fact that these observations were made at the same period, "souvent dans la même journée, sous un ciel également propice et précisément sur Ia même point de la planète."

The value nearest to 24 hours that Prof. Trouvelot obtained was $23 \mathrm{~h}$. $49 \mathrm{~m} .28 \mathrm{~s}$., and in giving this period he remarks that it is founded on the supposition that the spot had no proper motion. In referring to the period deduced by Schiapareili he says, "La cause probable de l'erreur de M. Schiaparelli semble résulter de ce fait que les taches $h$ et $k$, qui ont servi de base à ses conclusions, faisaient partie de la tache polaire méridionale qui, étant située centralement sur l'axe de rotation de la planète, semble rester stationnaire, comme cela se voit sur la tache polaire de Mars, quand elle se trouve réduite à de faibles dimensions." Taking into account many of the general features visible on the planet's surface, such as the rapid deformations of the horns and of the terminator, all these point to short periods of rotation, which, as Prof. Trouvelot points out, is "inconciliable avec la période de rotation, si lente et si inattendue, déduite par l'éminent astronome de Milan."

In concluding our remarks we cannot help mentioning the very complete way in which Prof. Trouvelot has taken into account the prior work in this interesting field of inquiry.

W. J. L.

\section{NOTES}

THE Iron and Steel Institute will meet at Liverpool from 'Tuesday, September 20, to Friday, the 23rd. Sir Frederick Abel will preside. The following papers will probably be read and discussed:-(Tuesday) on the condensation of ammonia from blast furnaces, by Sir L. Bell, F.R.S. ; on alloys of chrome and iron, by R. A. Hadfield; on the Liverpool overhead railway, by J. H. Greathead: (Wednesday) on the engineering laboratories in Liverpool, by Prof. H. S. Hele-Shaw; on the Siemens-Martin process at Witkowitz, Austria, by $P$. Kupelwieser ; on failures in the necks of chilled rolls, by C. A. Winder: (Thursday) on a new process for the elimination of 